\title{
Peripheral and hepatic insulin sensitivity in subjects with impaired glucose tolerance
}

\author{
T.S. Berrish ${ }^{1,2}$, C.S. Hetherington ${ }^{1,3}$, K. G.M.M. Albertit ${ }^{1,2}$, M. Walker ${ }^{1,2}$ \\ ${ }^{1}$ Human Diabetes and Metabolism Research Centre, University of Newcastle upon Tyne, Newcastle upon Tyne, UK \\ ${ }^{2}$ Department of Medicine, University of Newcastle upon Tyne, Newcastle upon Tyne, UK \\ ${ }^{3}$ Biomedical Mass Spectrometry Unit, University of Newcastle upon Tyne, Newcastle upon Tyne, UK
}

Summary Recent evidence suggests that the postprandial hyperglycaemia in impaired glucose tolerance is primarily due to impaired suppression of basal hepatic glucose output. This in turn appears to be secondary to decreased first phase insulin secretion, although decreased hepatic insulin sensitivity, which is a feature of non-insulin-dependent diabetes mellitus, might also play a role. Eight mildly overweight subjects with impaired glucose tolerance and eight closely matched control subjects with normal glucose tolerance underwent an intravenous glucose tolerance test to assess first phase insulin secretion. Insulin sensitivity was examined by a 150 -min hyperinsulinaemic-euglycaemic clamp. Somatostatin was infused from $150 \mathrm{~min}$ to suppress endogenous insulin secretion, and glucagon and insulin were replaced by constant infusion. Glucose with added dideuterated glucose (labelled infusion technique) was infused to maintain euglycaemia. First phase insulin secretion ( $\triangle$ 0-10 min insulin area $\div \Delta 0-10 \mathrm{~min}$ glucose area) was significantly decreased in the subjects with impaired glucose tolerance (median [range]: 1.2 $[0.2-19.4]$ vs $\left.9.1[2.6-14.5] \mathrm{mU} \cdot \mathrm{mmol}^{-1} ; p<0.01\right)$. During the clamp, circulating insulin $(93 \pm 8$ [mean $\pm \mathrm{SEM}$ ] and $81 \pm 10 \mathrm{mU} \cdot \mathrm{l}^{-1}$ ) and glucagon (54 \pm 4 and $44 \pm 6 \mathrm{ng} \cdot \mathrm{l}^{-1}$ ) levels were comparable. Total glucose disposal was decreased in subjects with impaired glucose tolerance $(2.78 \pm 0.27$ vs $4.47 \pm 0.53 \mathrm{mg} \cdot \mathrm{kg}^{-1} \cdot \min ^{-1} ; p<0.02$ ), and was primarily due to decreased non-oxidative glucose disposal. However, hepatic glucose output rates were comparable during the clamp $(0.38 \pm 0.10$ and $\left.0.30 \pm 0.18 \mathrm{mg} \cdot \mathrm{kg}^{-1} \cdot \mathrm{min}^{-1}\right)$. Therefore, the main defects in subjects with impaired glucose tolerance are decreased first phase insulin secretion and peripheral non-oxidative glucose disposal, but hepatic glucose output shows normal responsiveness to insulin. [Diabetologia (1995) 38: 699-704]

Key words Impaired glucose tolerance, insulin sensitivity, hepatic glucose output, insulin secretion, labelled infusion technique.
Non-insulin-dependent diabetes mellitus (NIDDM) is characterised by impaired insulin secretion and decreased insulin sensitivity. Despite extensive investi-

Received: 20 September 1994 and in revised form: 13 December 1994

Corresponding author: Dr. M. Walker, Department of Medicine, The Medical School, Framlington Place, Newcastle upon Tyne NE2 4HH, UK

Abbreviations: FPIS, First phase insulin secretion; PG, plasma glucose; NIDDM, non-insulin-dependent diabetes mellitus; IGT, impaired glucose tolerance; HGO, hepatic glucose output; IVGTT, intravenous glucose tolerance test; OGTT, oral glucose tolerance test. gation, however, the primary defect(s) leading to the development of NIDDM have not been defined.

As NIDDM is invariably preceded by a period of impaired glucose tolerance (IGT), attention has focused on this condition as a means of trying to elucidate the early metabolic abnormalities. Mitrakou and colleagues [1] showed that after the ingestion of an oral glucose load the elevated blood glucose levels in subjects with IGT were due to a failure to suppress basal hepatic glucose output (HGO). This was linked with a decrease in first phase insulin secretion (FPIS). However, decreased hepatic insulin sensitivity is a feature of NIDDM $[2,3]$, and thus a concurrent decrease in hepatic insulin sensitivity might 
have contributed to the persistently raised $\mathrm{HGO}$ in the IGT subjects. Previous studies in subjects with IGT have produced conflicting results, with evidence for normal [4] and decreased [5, 6] hepatic insulin sensitivity. However, in these studies no attempt was made to exclude the potentially confounding effect of different portal insulin levels between the IGT subjects and their respective control subjects.

Therefore, the aim of this study was to determine hepatic insulin sensitivity in a group of moderately overweight subjects with IGT by using somatostatin infusion to suppress endogenous insulin secretion and the labelled infusion technique to measure glucose turnover.

\section{Subjects and methods}

Patients. Eight males with IGT and eight males with normal glucose tolerance, none of whom had a family history of NIDDM, were matched for age and body mass index (BMI) (Table 1). None of the subjects were taking regular medication. Informed written consent was obtained from the subjects, and the study was approved by the Newcastle Health Authority and University of Newcastle upon Tyne Joint Ethics Committee.

Protocols. All subjects were taking a standard weight-maintaining diet, and were asked to avoid alcohol and severe exercise for $48 \mathrm{~h}$ prior to each study.

Each subject underwent a $75-\mathrm{g}(388 \mathrm{ml}$ degassed Lucazade, Smith Klein Beecham, Brentford, UK) oral glucose tolerance test (OGTT) following an overnight fast, and glucose tolerance was classified using World Health Organization criteria [7]. The diagnosis of impaired glucose tolerance was confirmed by a second OGTT.

An intravenous glucose tolerance test (IVGTT) was conducted in order to examine FPIS. Following an overnight fast, two cannulae were introduced under local anaesthetic. The first was placed retrogradely in a dorsal hand vein for arterialised venous blood sampling [8]. The hand was warmed in a heated hand box set at a temperature of $50^{\circ} \mathrm{C}$. The second cannula was placed in an antecubital vein, and $0.3 \mathrm{~g} \cdot \mathrm{kg}^{-1}$ glucose was administered over $1 \mathrm{~min}$ at time $0 \mathrm{~min}$ [9].

Insulin sensitivity was examined in each study using a combination of hyperinsulinaemic-euglycaemic clamp and glucose turnover techniques. Following an overnight fast, two cannulae were introduced and prepared as described above for the IVGTT. $\left[6,6{ }^{2} \mathrm{H}_{2}\right]$-labelled glucose (Tracer Technologies Inc., Somerville, Mass., USA) was infused (170 mg prime and $100 \mathrm{mg} \cdot \mathrm{h}^{-1}$ ) from 0 to $300 \mathrm{~min}$. From 150 to $300 \mathrm{~min}$, a combined infusion of somatostatin $\left(250 \mu \mathrm{g} \cdot \mathrm{h}^{-1}\right.$; DuraScan Odense, Denmark), soluble insulin $\left(0.05 \mathrm{U} \cdot \mathrm{kg}^{-1} \cdot \mathrm{h}^{-1}\right.$; NovoNordisk, Copenhagen, Denmark), and glucagon (27 $\mathrm{ng} \cdot \mathrm{kg}^{-1}$. $\mathrm{h}^{-1}$; NovoNordisk) was administered. Blood glucose concentration was maintained at fasting levels by an adjustable infusion of $20 \%$ (weight/volume) glucose solution [10], to which $\left[6,6-{ }^{2} \mathrm{H}_{2}\right]$-labelled glucose $\left(8 \mathrm{mg} \cdot \mathrm{gm}^{-1}\right.$ unlabelled glucose; [11]) was added in order to maintain basal plasma enrichments (labelled infusion technique). Substrate oxidation rates were determined by indirect calorimetry from 130 to $150 \mathrm{~min}$ and 280 to $300 \mathrm{~min}$ using a Deltatrac Indirect Calorimeter (Datex Instrumentation Corp., Helsinki, Finland). A timed urine collection was made for the duration of the study for the determination of the urinary nitrogen excretion rate.
Table 1. Anthropometric and OGTT data (mean \pm SEM) for the impaired glucose tolerant (IGT) and normal glucose tolerant (NGT) subjects

\begin{tabular}{llcc}
\hline & $\begin{array}{l}\text { IGT } \\
(n=8)\end{array}$ & $\begin{array}{l}\text { NGT } \\
(n=8)\end{array}$ & $p$ value \\
\hline Age (years) & $55 \pm 3$ & $54 \pm 3$ & NS \\
BMI $\left(\mathrm{kg} \cdot \mathrm{m}^{-2}\right)$ & $27 \pm 1$ & $27 \pm 1$ & NS \\
$\begin{array}{llcl}\text { Plasma glucose level } \\
\text { Visit 1 }\end{array}$ & & & \\
Fasting $\left(\mathrm{mmol} \cdot \mathrm{l}^{-1}\right)$ & $5.8 \pm 0.1$ & $5.2 \pm 0.1$ & $<0.01$ \\
2-h $\left(\mathrm{mmol} \cdot \mathrm{I}^{-1}\right)$ & $9.7 \pm 0.6$ & $5.3 \pm 0.4$ & $<0.001$ \\
Visit 2 & & & \\
Fasting $\left(\mathrm{mmol} \cdot \mathrm{l}^{-1}\right)$ & $5.8 \pm 0.1$ & - & - \\
2-h $\left(\mathrm{mmol} \cdot \mathrm{I}^{-1}\right)$ & $8.7 \pm 0.3$ & - & - \\
\hline
\end{tabular}

Sampling and analytical procedures. During the OGTT, fasting and 2 -h plasma glucose levels were measured. Arterialised venous blood was sampled for plasma glucose and serum insulin determinations at intervals throughout the IVGTT as previously described [9]. During the insulin sensitivity study, blood was sampled at intervals from 130 to $300 \mathrm{~min}$ for whole blood glucose, serum insulin and C-peptide, plasma glucagon and non-esterified fatty acid (NEFA) levels. Plasma glucose concentrations and enrichments were determined during the prestudy period ( -15 and $0 \mathrm{~min}$ ), and at 5-min intervals from 130 to $150 \mathrm{~min}$ (basal period) and 280 to $300 \mathrm{~min}$ (clamp period) for the measurement of glucose turnover rates.

Glucose concentrations were measured by the glucose oxidase method using a glucose analyser (interstudy CV, 3.5\%; Yellow Springs Instrument, Yellow Springs, Ohio, USA). Serum insulin concentrations were determined using a two-site monoclonal enzyme linked immunoabsorbant assay [12] which is highly specific for insulin (cross reactivity in our hands; intact proinsulin $0.5 \%$ at $1000 \mathrm{pmol} \cdot \mathrm{l}^{-1}$ and $32,33 \mathrm{split}$ proinsulin $1.2 \%$ at $4200 \mathrm{pmol} \cdot \mathrm{l}^{-1}$ ). Serum C-peptide (NovoNordisk) and plasma glucagon [13] concentrations were measured by radioimmunosassay (interassay CVs; 6.2 and $9.5 \%$, respectively). Plasma NEFA levels were measured by centrifugal enzymatic analysis (interassay $\mathrm{CV}, 3 \%$; Wako NEFA kit, Wako Chemicals, Neuss, Germany) based on the method of Knox and Jones [14]. Urinary nitrogen concentrations were determined by the Kjeldhal method (Kjeltec Analyser, Perstorp Analytical Ltd., Perstorp, Sweden), and blood urea concentrations were measured before and after the clamp to correct for changes in the urea pool [15].

Plasma $\left[6,6-{ }^{2} \mathrm{H}_{2}\right]$-labelled glucose enrichment was determined by first deproteinizing the plasma $(1 \mathrm{ml})$ with $3.5 \% 5-$ sulphosalicylic acid. The extracted glucose was derivitized by the addition of 1-butanoboronic acid in pyridine $(10 \mathrm{mg}$. $\mathrm{ml}^{-1}$ ), followed by acetic anhydride $[16,17]$. After drying under nitrogen, the derivatives were resuspended in ethylacetate and measured on a Finnigan Mat 1050 gas chromatography-mass spectrometer (Finnigan Corporation, Sunnyvale, Calif., USA). Molecular ions 297 and 299 were detected, from which the percent enrichment was calculated [17]. This was corrected against a standard ( $5 \%$ enrichment) and for the background contribution (pre-study samples). The $\left[6,6{ }^{2} \mathrm{H}_{2}\right]-\mathrm{la}-$ belled glucose enrichments of the continuous tracer infusions and of the labelled $20 \%$ glucose solutions infused during the clamps were determined in order to calculate the overall tracer infusion rates $(F)$. 
Table 2. Individual first phase insulin secretion values (mU . $\mathrm{mmol}^{-1}$ )

\begin{tabular}{lcl}
\hline Subject & $\begin{array}{l}\text { Impaired glucose } \\
\text { tolerance }\end{array}$ & $\begin{array}{l}\text { Normal glucose } \\
\text { tolerance }\end{array}$ \\
\hline 1 & 0.2 & 13.6 \\
2 & 1.3 & 14.5 \\
3 & 19.4 & 11.8 \\
4 & 1.3 & 8.8 \\
5 & 3.4 & 2.6 \\
6 & 0.2 & 5.0 \\
7 & 1.0 & 9.4 \\
8 & 1.1 & 4.0 \\
Median & 1.2 & $9.1^{\mathrm{a}}$ \\
\hline
\end{tabular}

${ }^{a} p<0.01$ impaired vs normal glucose tolerance

\section{Statistical analysis}

First phase insulin secretion (FPIS) was defined as $\Delta 0-10 \mathrm{~min}$ insulin area divided by $\Delta 0-10$ min glucose area which has been shown to be the most reproducible assessment when compared with other standard methods [9].

The Steele equations [18] were used to calculate the rates of glucose disposal $\left(R_{d}\right)$ and appearance $\left(R_{a}\right)$ during the basal and clamp periods, using values of $200 \mathrm{ml} \cdot \mathrm{kg}^{-1}$ and 0.65 for the glucose space and pool fraction, respectively. The enrichments were smoothed by using the moving-average method using three successive measurements. During the clamp period, the tracer infusion rate $(\mathrm{F})$ was calculated as the sum of the continuous $\left[6,6-{ }^{2} \mathrm{H}_{2}\right]$-glucose infusion rate and the rate of infusion of the tracer given with the $20 \%$ glucose solution [19]. HGO was taken to equal $R_{a}$ during the basal period, and the difference between $\mathrm{R}_{\mathrm{a}}$ and the total (unlabelled and labelled) glucose infusion rate ( $\mathrm{M}$ value) during the clamp period.

Substrate oxidation rates were calculated using standard equations $[20,21]$, and the rate of non-oxidative glucose disposal was calculated as the difference between the rates of glucose disposal $\left(\mathrm{R}_{\mathrm{d}}\right)$ and glucose oxidation.

Statistical comparison between the IGT and control groups was by the unpaired $t$-test, except for the FPIS measurements which was by the Mann-Whitney U test. For the insulin sensitivity studies, comparison between the basal and clamp periods within subject groups was by Student's paired $t$-test. Data are presented as the mean \pm SEM, except for the FPIS measurements which were summarised as the median and range.

\section{Results}

\section{OGTT and IVGTT}

The plasma glucose concentrations for the OGTTs are summarised in Table 1 . The fasting and 2 -h plasma glucose levels were significantly higher in the IGT subjects compared with the normal glucose tolerant (NGT) control subjects (visit 1). All IGT subjects remained in the IGT classification on retesting (visit 2), and the interval between the first and second visits ranged from 3 weeks to 18 months.

The individual FPIS measurements are shown in Table 2. FPIS was significantly lower in the IGT sub-
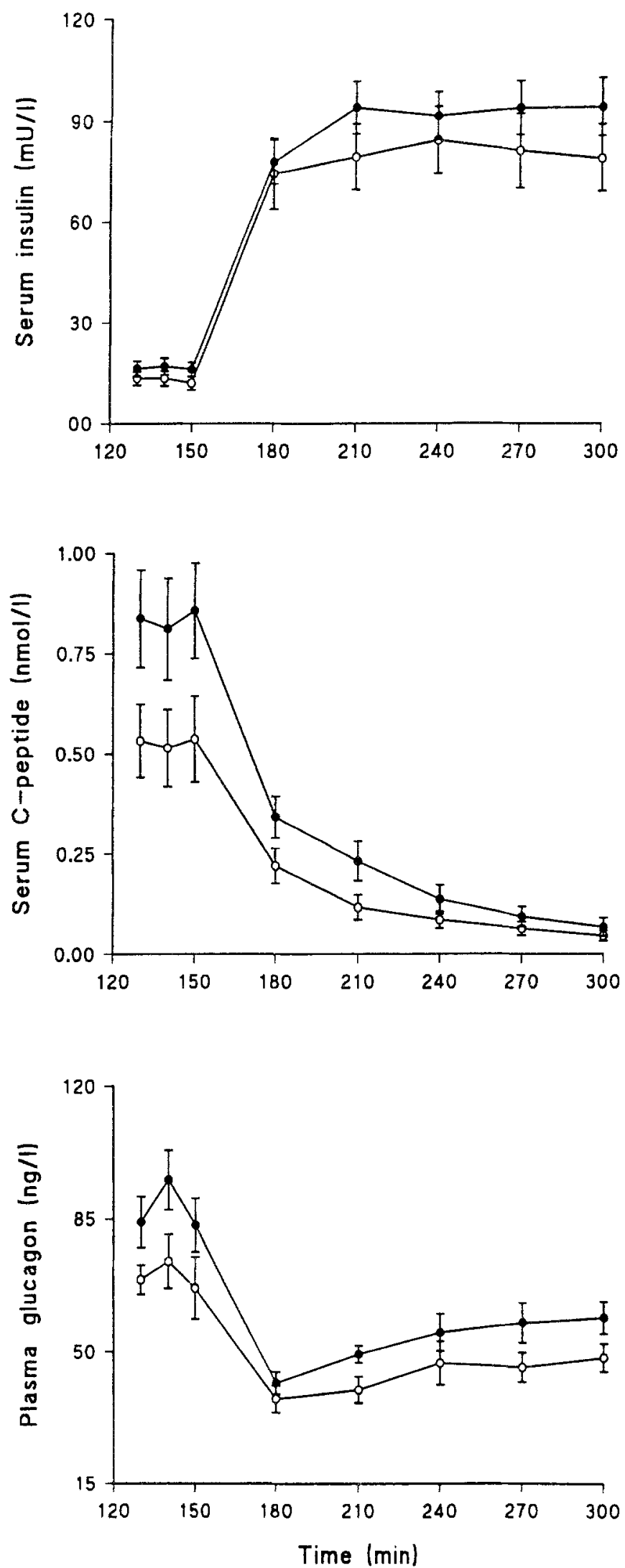

Fig. 1. Serum insulin, C-peptide, and plasma glucagon concentrations (mean \pm SEM) for the impaired (IGT) (•) and normal (NGT) (O) glucose tolerance subjects 


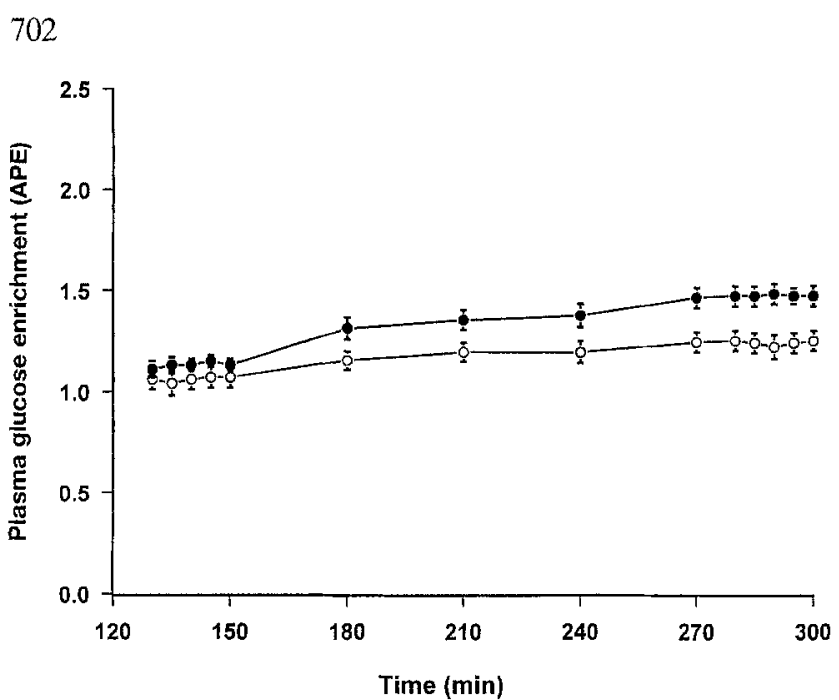

Fig. 2. Plasma glucose enrichments (mean \pm SEM) for the impaired (IGT) (•) and normal (NGT) (O) glucose tolerance subjects

jects (median [range]: 1.2 [0.2-19.4] vs 9.1 [2.6-14.5] $\mathrm{mU} \cdot \mathrm{mmol}^{-1}$; IGT vs NGT, $\left.p<0.01\right)$.

\section{Insulin sensitivity studies}

Substrate and hormone concentrations. Plasma glucose levels tended to be higher in the IGT subjects during the basal $\left(5.5 \pm 0.1\right.$ and $\left.5.2 \pm 0.1 \mathrm{mmol} \cdot \mathrm{l}^{-1}\right)$ and clamp $\left(5.4 \pm 0.1\right.$ and $\left.5.1 \pm 0.1 \mathrm{mmol} \cdot \mathrm{l}^{-1}\right)$ periods, although these differences were not statistically significant.

Basal serum insulin and C-peptide levels tended to be higher in the IGT subjects (Fig.1), but failed to reach statistical significance. Following the infusion of insulin from $150 \mathrm{~min}$, the serum insulin concentrations reached comparable levels $(93 \pm 8$ and $81 \pm$ $10 \mathrm{mU} \cdot \mathrm{l}^{-1}$; IGT and NGT subjects, NS) during the clamp period, while serum C-peptide concentrations were suppressed to similar levels $(0.17 \pm 0.04$ and $0.10 \pm 0.02 \mathrm{nmol} \cdot l^{-1}$; IGT and NGT subjects, NS).
T.S. Berrish et al.: Insulin sensitivity in impaired glucose tolerance

Plasma glucagon levels (Fig. 1) were not significantly different during the basal ( $85 \pm 7$ and $70 \pm 6 \mathrm{ng} \cdot \mathrm{1}^{-1}$; IGT and NGT subjects) and clamp (54 \pm 4 and $44 \pm 6 \mathrm{ng} \cdot 1^{-1}$; IGT and NGT subjects) periods. Plasma NEFA concentrations were similar during the basal period $\left(0.70 \pm 0.07\right.$ and $0.61 \pm 0.06 \mathrm{mmol} \cdot \mathrm{l}^{-1}$; IGT and NGT subjects, NS), and were suppressed to the same degree following the infusion of insulin $\left(0.24 \pm 0.05\right.$ and $0.14 \pm 0.04 \mathrm{mmol} \cdot \mathrm{l}^{-1} ;$ IGT and NGT subjects, NS).

Glucose disposal and HGO rates. Basal HGO rates were comparable $(2.07 \pm 0.16$ and $1.88 \pm 0.13 \mathrm{mg}$. $\mathrm{kg}^{-1} \cdot \mathrm{min}^{-1}$; IGT and NGT subjects, NS). The addition of $\left[6,6-{ }^{2} \mathrm{H}_{2}\right]$-glucose to the $20 \%$ glucose solution prevented a fall in the basal plasma enrichment following the infusion of insulin (Fig. 2). The individual glucose infusion and turnover measurements for the clamp period are shown in Table 3 . The glucose infusion ( $M$ value, $p<0.05$ ) and total glucose disposal $\left(\mathrm{R}_{\mathrm{d}}, p<0.02\right)$ rates were significantly lower in the IGT subjects, while there was no significant difference between the $\mathrm{HGO}$ rates (Table 3 ) during the clamp period $\left(0.38 \pm 0.10\right.$ and $0.30 \pm 0.18 \mathrm{mg} \cdot \mathrm{kg}^{-1}$. $\mathrm{min}^{-1}$; IGT and NGT subjects).

Substrate oxidation and non-oxidative glucose disposal rates. As shown in Table 4, comparison of the two groups revealed no significant differences for the lipid and carbohydrate oxidation rates during the basal and clamp periods. However, the changes in these substrate oxidation rates following the infusion of insulin were significantly less in the IGT subjects. Protein oxidation rates were comparable for the two subject groups $(0.52 \pm 0.04$ and $0.60 \pm$ $0.06 \mathrm{mg} \cdot \mathrm{kg}^{-1} \cdot \mathrm{min}^{-1} ;$ IGT and NGT subjects, NS), although the non-oxidative glucose disposal rate was significantly lower during the clamp period in the IGT subjects $\left(1.57 \pm 0.26\right.$ vs $2.96 \pm 0.34 \mathrm{mg} \cdot \mathrm{kg}^{-1}$. $\left.\min ^{-1}, p<0.01\right)$.

Table 3. Individual $M$ values and rates of hepatic glucose output (HGO) and glucose turnover $\left(R_{d}\right.$ and $\left.R_{a}\right)$ for the clamp period. Values are in $\mathrm{mg} \cdot \mathrm{kg}^{-1} \cdot \mathrm{min}^{-1}$

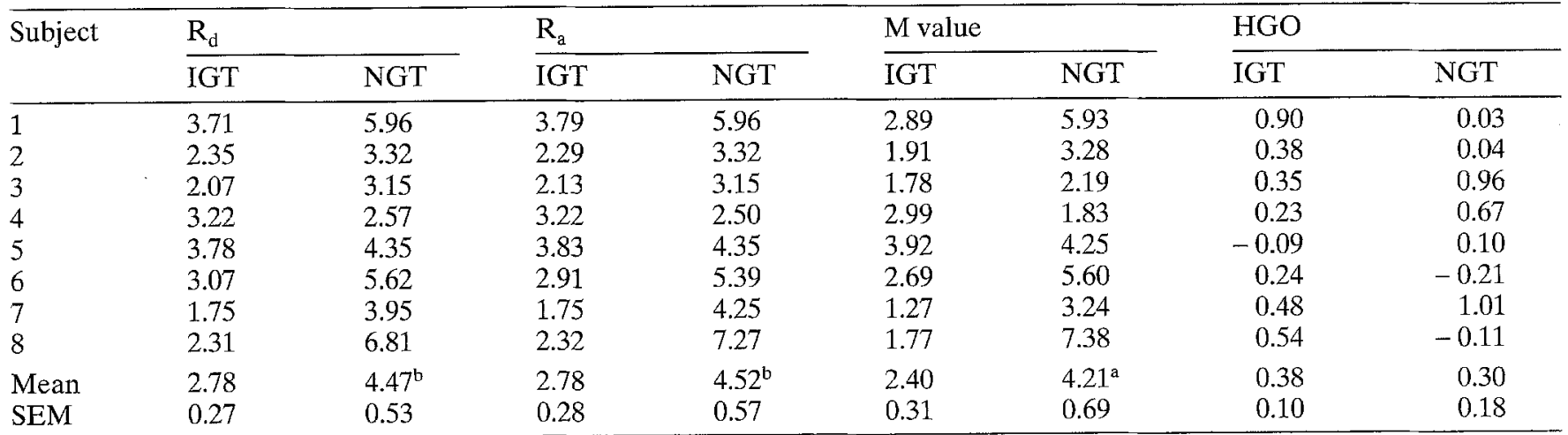

${ }^{\mathrm{a} p} p<0.05 ;{ }^{\mathrm{b}} p<0.02$ impaired (IGT) vs normal (NGT) glucose tolerance 
Table 4. Substrate oxidation rates $\left(\mathrm{mg} \cdot \mathrm{kg}^{-1} \cdot \mathrm{min}^{-1}\right)$ during the basal and clamp periods, and the differences between the two periods. Values presented as mean \pm SEM

\begin{tabular}{llcc}
\hline & & $\begin{array}{l}\text { IGT } \\
(n=8)\end{array}$ & $\begin{array}{l}\text { NGT } \\
(n=8)\end{array}$ \\
\hline Lipid & Basal & $0.92 \pm 0.10$ & $0.99 \pm 0.08$ \\
oxidation & Clamp & $0.67 \pm 0.10^{\mathrm{a}}$ & $0.56 \pm 0.10^{\mathrm{a}}$ \\
& Difference & $-0.25 \pm 0.04$ & $-0.43 \pm 0.05^{\mathrm{b}}$ \\
Carbohydrate & Basal & $0.81 \pm 0.23$ & $0.50 \pm 0.19$ \\
oxidation & Clamp & $1.22 \pm 0.25^{\mathrm{a}}$ & $1.51 \pm 0.28^{\mathrm{a}}$ \\
& Difference & $+0.41 \pm 0.08$ & $+1.01 \pm 0.17^{\mathrm{c}}$ \\
\hline
\end{tabular}

a $p<0.01$ Basal vs Clamp

${ }^{\mathrm{b}} p<0.02 ;{ }^{\mathrm{c}} p<0.01$ impaired (IGT) vs normal (NGT) glucose tolerance

\section{Discussion}

First phase insulin secretion (FPIS), measured with a highly specific assay, was diminished in the group of subjects with IGT, in keeping with the observation of decreased early insulin secretion reported in other studies [1, 22-24]. Mitrakou and colleagues [1] suggested that, following an oral glucose load, the abnormally raised blood glucose levels in IGT subjects was due to a failure to suppress basal HGO. The decreased FPIS would provide a straightforward explanation for this observation. However, hepatic sensitivity to insulin is decreased in established NIDDM $[2,3]$, and if this is a feature of IGT then it might also contribute to the failure to suppress basal HGO normally in the postprandial state.

Several previous studies have examined hepatic insulin sensitivity in IGT [4-6], although the findings have been conflicting. In these studies, however, no attempt was made to ensure that the portal insulin levels were comparable in the IGT subjects and their control subjects by suppressing endogenous insulin secretion and replacing it with a constant infusion. This was achieved in the present study by the infusion of somatostatin, and confirmed by the comparable circulating $\mathrm{C}$-peptide levels in the two-subject groups during the clamp period. By the same token, the comparable plasma glucagon levels were important in avoiding differential effects on HGO. However, plasma glucagon levels were shown to be suppressed to a lesser degree in IGT subjects following an oral glucose load [1], which might well influence the hepatic response to insulin in the physiological setting of the postprandial state.

Another potential problem in the measurement of hepatic insulin sensitivity is the calculation of negative $\mathrm{HGO}$ rates when using the Steele equations. Recent studies have shown that such errors can be minimised by maintaining plasma enrichments at basal levels during the hyperinsulinaemic clamp by the co-infusion of tracer with the unlabelled glucose solution $[11,19]$ (labelled infusion technique). This ap- proach has not been previously applied to assess hepatic insulin sensitivity in subjects with IGT. In the present study, a fall in plasma enrichment from basal levels was prevented (Fig. 2) by using this technique.

Using these methods, $\mathrm{HGO}$ rates were shown to be comparable in the subject groups during the clamp period. Thus, hepatic insulin sensitivity is normal in mildly overweight subjects with IGT, and the failure to suppress basal $\mathrm{HGO}$ in the postprandial state appears to be due solely to the decreased FPIS. Moreover, it would suggest that the decreased hepatic insulin sensitivity previously reported in NIDDM is not a primary defect. It is interesting to note, however, that markedly obese subjects with IGT were recruited in the two studies in which hepatic insulin sensitivity was decreased $[5,6]$. Whether obesity per se modulates HGO in subjects with IGT requires further assessment.

While hepatic insulin sensitivity was normal, peripheral insulin sensitivity was markedly diminished in the IGT subjects and supports the observations of previous studies $[4,25]$. Skeletal muscle is the principal tissue site for peripheral insulin-stimulated glucose disposal [26], and is therefore the likely site of the insensitivity in the IGT subjects. In addition, the major defect was in non-oxidative glucose disposal which primarily reflects glucose storage as glycogen [27]. Thus, IGT subjects have a combination of decreased FPIS and peripheral insulin insensitivity. Eriksson and colleagues [4] noted the same combination in IGT first degree relatives of NIDDM patients, while the decreased peripheral insulin sensitivity was the only abnormality in the relatives with normal glucose tolerance.

Abnormalities of lipid metabolism have been reported in obese subjects with IGT [5]. In the present study, plasma NEFA levels and lipid oxidation rates were normal during the basal and clamp periods in the IGT subjects. The absolute carbohydrate oxidation rates were similarly normal. However, the changes in the basal substrate oxidation rates following the infusion of insulin were significantly less in the IGT subjects. This would suggest that the regulatory effect of insulin on substrate oxidation is slightly impaired in IGT, which may be due to the operation of the glucose-fatty acid cycle [28] which has been described in NIDDM [29].

While FPIS was diminished in the group of IGT subjects as a whole, one individual (subject number 3 , Table 2) with mildly impaired glucose tolerance had a value above the range of the control subjects. This is in keeping with the observation of Groop and colleagues [30] that FPIS appears to be increased in the very early stages of impaired glucose tolerance.

In conclusion, therefore, the failure to suppress basal $\mathrm{HGO}$ normally in the postprandial state in mildly overweight IGT subjects appears to be primar- 
ily due to decreased FPIS as hepatic insulin sensitivity is normal.

Acknowledgements. We thank Sister M.Brown, Sister M. Miller, and Ms. L. Ashworth and her staff for their technical help. T.S. B. was supported by the Ministry of Higher Education, Libya. This work was funded by the joint Medical Research Council/British Diabetic Association Diabetes Special Project Grant.

\section{References}

1. Mitrakou A, Kelley D, Mokan M et al. (1992) Role of reduced suppression of glucose production and diminished early insulin release in impaired glucose tolerance. $N$ Engl J Med 326: 22-29

2. Firth R, Bell P, Rizza R (1987) Insulin action in non-insulindependent diabetes mellitus: the relationship between hepatic and extrahepatic insulin resistance and obesity. Metabolism 36: 1091-1095

3. Groop LC, Bonadonna RC, DelPrato S et al. (1989) Glucose and free fatty acid metabolism in non-insulin-dependent diabetes mellitus. Evidence for multiple sites of insulin resistance. J Clin Invest 84: 205-213

4. Eriksson J, Franssila-Kallunki A, Ekstrand A et al. (1989) Early metabolic defects in persons at increased risk for non-insulin-dependent diabetes mellitus. $\mathrm{N}$ Engl $\mathrm{J}$ Med 321: 337-343

5. Robertson DA, Singh BM, Nattrass M (1991) Impaired glucose tolerance in obesity is associated with insensitivity to insulin in multiple aspects of metabolism as assessed by a low dose incremental insulin infusion technique. Diabet Med 8: 718-725

6. Lillioja S, Mott DM, Howard BV et al. (1988) Impaired glucose tolerance as a disorder of insulin action. N Engl J Med 318: $1217-1225$

7. World Health Organization (1985) Diabetes mellitus, report of a WHO study group. Technical Report Series 727. Geneva: WHO

8. Abumrad NN, Rabin D, Diamond MP, Lacy WW (1981) Use of a heated superficial hand vein as an alternative site for the measurement of amino acid concentrations and for the study of glucose and alanine kinetics in man. Metabolism 30: 936-940

9. Koschmann M, Alford FP, Ward GM, Walters J, Colman PG, Harrison LC (1992) Reproducibility of estimating first phase insulin responses to intravenous glucose. Diab Nutr Metab 5: 73-79

10. DeFronzo RA, Tobin JD, Andres R (1979) Glucose clamp technique: a method for quantifying insulin secretion and resistance. Am J Physiol 237 (3): E214-E223

11. Powrie JK, Smith GD, Hennessy TR et al. (1992) Incomplete suppression of hepatic glucose production in non-insulin dependent diabetes mellitus measured with $\left[6,6-{ }^{2} \mathrm{H}_{2}\right]$ glucose enriched glucose infusion during hyperinsulinaemic euglycaemic clamps. Eur $\mathrm{J}$ Clin Invest 22 : 244-253

12. Anderson L, Dineson B, Jorgenson PN, Poulsen F, Roder ME (1993) Enzyme immonoassay for intact human insulin in serum or plasma. Clin Chem 39: 578-582
13. Orskov H, Thomsen HG, Yde H (1969) Wick chromatography for rapid and reliable immunoassay of insulin, glucagon and growth hormone. Nature 219: 193-195

14. Knox DP, Jones DG (1984) Automated enzymatic determination of plasma free fatty acids by centrifugal analysis. $J$ Autom Chem 6: 152-154

15. Tappy L, Owen OE, Boden G (1988) Effect of hyperinsulinemia on urea pool size and substrate oxidation rates. Diabetes 37: 1212-1216

16. Wiecko J, Sherman WR (1976) Boroacetylation of carbohydrates. Correlations between structure and mass spectral behaviour in monoacetylhexose cyclic boronic esters. J Am Chem Soc 98: 7631-7637

17. Bier DM, Arnold KJ, Sherman WR, Holland WH, Holmes WF, Kipnis DM (1977) In vivo measurement of glucose and alanine metabolism with stable isotope tracers. Diabetes 26: $1005-1015$

18. Steele R (1959) Influences of glucose loading and of injected insulin on hepatic glucose output. Ann NY Acad Sci 82: $420-430$

19. Levy JC, Brown G, Matthews DR, Turner RC (1989) Hepatic glucose output in humans measured with labeled glucose to reduce negative errors. Am J Physiol 257 (Endocrinol Metab 20): E 531-E 540

20. Frayn KN (1983) Calculation of substrate oxidation rates in vivo from gaseous exchange. J Appl Physiol 55: 628-634

21. Ferrannini E (1988) The theoretical basis of indirect calorimetry: a review. Metabolism 37: 287-301

22. Yoneda H, Ikegami H, Yamamoto Y et al. (1992) Analysis of early-phase insulin responses in nonobese subjects with mild glucose intolerance. Diabetes Care 15: 1517-1521

23. Davies MJ, Rayman G, Grenfell A, Gray IP, Day JL, Hales CN (1994) Loss of the first phase insulin response to intravenous glucose in subjects with persistent impaired glucose tolerance. Diabet Med 11: 432-436

24. Motala AA, Omar MAK (1994) Evidence for impaired pancreatic beta cell function in South African Indians with impaired glucose tolerance. Diabet Med 11: 437-444

25. Sacca L, Orofino G, Petrone A, Vigorito C (1984) Differential roles of splanchnic and peripheral tissues in the pathogenesis of impaired glucose tolerance. J Clin Invest 73 : 1683-1687

26. Yki-Järvinen H, Young AA, Lamkin C, Foley JE (1987) Kinetics of glucose disposal in whole body and across the forearm in man. J Clin Invest 79: 1713-1719

27. Lillioja S, Mott DM, Zawadzki JK, Young AA, Abbott WG, Bogardus C (1986) Glucose storage is a major determinant of in vivo "insulin resistance" in subjects with normal glucose tolerance. J Clin Endocrinol Metab 62: 922927

28. Randle PJ, Garland PB, Hales CN, Newsholme EA (1963) The glucose-fatty acid cycle. Its role in insulin sensitivity and the metabolic disturbances of diabetes mellitus. Lancet I: 785-789

29. Golay A, DeFronzo RA, Ferrannini E et al. (1988) Oxidative and non-oxidative glucose metabolism in non-obese type 2 (non-insulin-dependent) diabetic patients. Diabetologia 31: 585-591

30. Groop LC, Widen E, Ferrannini E (1993) Insulin resistance and insulin deficiency in the pathogenesis of type 2 (non-insulin-dependent) diabetes mellitus: errors of metabolism or of methods? Diabetologia 36: 1326-1331 